\title{
Dietary calcium intake and bone mineral density among Macedonian women
}

\section{Daniela Nikolovska Nedelkoska, Tanja Tefova, Zora Uzunoska}

\section{St. Kliment Ohridski University, Veles, Republic of Macedonia}

Keywords:

Osteoporosis

Calcium

Bone

Mineral

Postmenopausal

Women

\section{Article history:}

Received

18.07.2018

Received in revised form 25.09.2018

Accepted 03.12.2018

\section{Corresponding} author:

Daniela Nikolovska

Nedelkoska

E-mail:

daniela.nedelkoska@, uklo.edu.mk

DOI:

$10.24263 / 2310-$

$1008-2018-6-2-8$

\section{Abstract}

Introduction. Osteoporosis is a complex, multi-factorial bone disease leading to increased risk of fracture. Calcium as a nutrient is associated with the formation and metabolism of bone. The inadequate calcium intake leads to decreased bone mineralization and consequently an increased risk of osteoporosis.

Materials and methods. The study group was constituted by 104 postmenopausal women. Bone mineral density (BMD) at the participants' lumbar spin and hip was measured by dual-energy X-ray absorptiometry (DXA). The daily calcium intake (DCI) was assessed using a validated quantitative food frequency questionnaire (FFQ). Each participant also completed a core questionnaire that included general demographic data as well as questions about personal and family history of fractures, menopause onset, lifestyle behaviors, and corticosteroids use.

Results and discussion. The mean daily calcium intake among our study participants was $854.3 \pm 260.4 \mathrm{mg}$ which is below the calcium recommended nutrient intake (RNI) for postmenopausal women. This study's findings confirmed that the reduction of the bone mineral density (BMD), reported using $\mathrm{T}$-scores, depends on age and choice of measurement site. Our results also showed that higher body mass and body mass index (BMI) in participants are associated with higher BMD. The reduced bone density among postmenopausal women was related with the existence of previous personal fractures and the family history of fractures in diagnosed persons. The insight into exogenous risk factors of osteoporosis in this study showed that the most of the participants consume caffeine every day and have insufficient physical activity and sun exposure.

Conclusions. Education on the importance of calcium in the diet and knowledge on the lifestyle factors that affect bone loss are needed toward decreasing risk for osteoporosis and related fractures in postmenopausal women. 


\section{Introduction}

Osteoporosis is a metabolic bone disease characterized by low bone mineral density (BMD) and deteriorated microarchitecture of the bone tissue, with a consequent increase in bone fragility and susceptibility to bone fractures [1]. The disease affects approximately 200 million people worldwide [2] and takes a huge personal and economic toll. Osteoporosis can not be cured but results can be reached in the context of its prevention and delayed progression [3].

The World Health Organization (WHO) classifies osteoporosis as one of the ten most important diseases connected with the progress of civilization in the modern world. It is a disease whose incidence increases with age. Osteoporosis can occur in different life periods; however, women in the postmenopausal age and the elderly persons (over 70 years old) are the riskiest population groups for its development [4]. Osteoporosis is a big public health problem associated with age-related fracture, most frequently of the hip, vertebrae, distal forearm and humerus [5]. The measurement of bone mineral density by dual-energy X-ray absorptiometry (DXA) is widely used in assessing bone strength and predicting the risk of fracture [6]. Many factors, including genetics, age, gender, endocrine system, as well as other modifiable risk factors such as nutrition, physical activity, smoking and alcohol intake affect bone density and can therefore influence the onset of the disease [3].

Calcium is a nutrient that is associated with the formation and metabolism of bone [7]. In the last decades, the role of calcium in bone health has been comprehensively examined but unfortunately, there is a significant proportion of some population groups in the western countries who fail to reach the recommended calcium intake [8]. Although adequate calcium intake is important throughout the whole life, it is especially important in childhood and adolescence (because of fast skeleton growth), and for postmenopausal women and elderly persons (whose rate of bone mass loss is high) [9] . Therefore, ensuring adequate calcium intake throughout lifetime leads to decreased risk for osteoporosis and related fractures in adults [10].

The objectives of our study were to screen the bone mineral density and to assess the daily calcium intake among Macedonian postmenopausal women. Also, this study was aimed to gain insight into the risk factors that affect bone density and can therefore influence the onset and the progression of osteoporosis.

\section{Materials and methods}

The study group was constituted by 104 postmenopausal women at the age from 49 to 82. Arithmetic mean of the examined women's age was $64,7 \pm 7,6$ years. Women were informed about voluntary and anonymous participation in the study, and that the obtained results were collected only for scientific purposes. Eligibility criteria for the participants were: being postmenopausal, free of serious medical conditions and have clinical symptoms of osteoporosis. All women underwent anthropometric measurements (body mass, height, the calculation of body mass index (BMI)).

Bone mineral density (BMD) assessment. BMD at the participants' lumbar spin and hip was measured by dual-energy X-ray absorptiometry (DXA) at the Department for Radiological Diagnostics within PHI Clinical hospital 'Dr. Trifun Panovski' in Bitola. Dual energy X-ray absorptiometry is considered as a golden standard for measuring bone mineral density and it is most common method for diagnosing primary osteoporosis which is usually 
related to age and postmenstrual period, as well as for diagnosing secondary osteoporosis (osteoporosis caused by other factors such as hormonal imbalance, certain diseases or taking medications) [11]. The bone mineral density measurement results were interpreted in accordance with the operational definition of osteoporosis given by WHO [6]. BMD was reported as a T-score, defined as the difference in number of standard deviations (SD) from the mean BMD of a normally distributed young adult reference population. WHO proposes four categories for women: Normal - BMD higher than 1 SD below the young adult reference mean (T-score $\geq-1$ ); Low bone mass (osteopenia) - BMD between 1 and $2.5 \mathrm{SD}$ below the young adult mean (T-score $<-1$ and $>-2.5$ ); Osteoporosis - BMD lower than and equal to $2.5 \mathrm{SD}$ below the young adult mean (T-score $\leq-2.5$ ); and Severe osteoporosis - BMD lower than $2.5 \mathrm{SD}$ below the young adult mean and the presence of one or more fragility fractures.

Questionnaires. Each participant completed a core questionnaire that included general demographic data as well as questions about personal and family history of fracture, menopause onset, lifestyle behaviors, and corticosteroids use. The daily calcium intake (DCI) was assessed using a validated quantitative food frequency questionnaire (FFQ), that was originally developed for measuring dietary calcium intake in Croatian postmenopausal women [12]. The questionnaires were given to participants by researchers in person before the participants' X-ray absorptiometry examination.

Statistical analysis. The statistical analyses were performed with SPSS statistical software program (SPSS version 11.0.1 PC, USA, IL). All statistical tests were considered significant at $\mathrm{p} \leq 0.05$.

\section{Results and discussion}

Of the total population group in this study $(\mathrm{n}=104)$, in accordance with the obtained results for the T-score of the lumbar spine and T-score of the hip, 53 participants $(50.96 \%)$ showed osteoporotic, 42 participants $(40.38 \%)$ osteopenic, whereas 9 participants $(8.65 \%)$ normal BMD. Personal fragility fractures were reported by $19.23 \%$, while $8.65 \%$ of the participants had a history of family fractures.

Descriptive characteristics of the participants, the T-score values and their DCI (mean \pm $\mathrm{SD})$ are presented in Table 1. It was determined that the average daily calcium intake in the female respondents is $854.3 \pm 260.4 \mathrm{mg}$, whereas the average body mass index (BMI) has reference $27.7 \pm 3.6 \mathrm{~kg} / \mathrm{m}^{2}$. In average, female respondents enter menopause from the age of 47.5 4.9. The obtained results from the BMD measurement showed that at the level of the whole population group, the average reference of $\mathrm{T}$-score of the hip is $-1.73 \pm 1.01$ whereas the average reference of $\mathrm{T}$-score of the lumbar spine is $-1.83 \pm 1.30$. None of the participants had reference $\mathrm{BMI}<18,5 \mathrm{~kg} / \mathrm{m}^{2}$. 
Descriptive characteristics of participants, T-score values and DCI

\begin{tabular}{|l|c|c|c|c|}
\hline & Min & Max & $\overline{\mathbf{x}}$ & SD \\
\hline Age $($ years $)$ & 49 & 82 & 64.7 & 7.6 \\
\hline Body mass $(\mathrm{kg})$ & 50 & 95 & 71.46 & 9.67 \\
\hline Height $(\mathrm{m})$ & 1.5 & 1.75 & 1.61 & 0.05 \\
\hline BMI $\left(\mathrm{kg} / \mathrm{m}^{2}\right)$ & 20.28 & 39.73 & 27.7 & 3.6 \\
\hline Menopause onset (years $)$ & 35 & 58 & 47.5 & 4.9 \\
\hline Hip T-score & -4.1 & 1.4 & -1.73 & 1.01 \\
\hline Lumbar spine T-score & -4.7 & 2.6 & -1.83 & 1.30 \\
\hline DCI $($ mg/day) & 366.4 & 1689.01 & 854.3 & 260.4 \\
\hline
\end{tabular}

$n=104, \bar{x}-$ mean, $S D-$ standard deviation

Pearson's correlation coefficients were used to assess associations between T-score and DCI, body mass, height, age and menopause onset. The results of statistical analysis are shown in Table 2. Present results demonstrated that correlation between DCI and T-score of the spine $(r=-0.153, p=0.120)$, as well as the T-score of the hip $(r=-0.155, p=0.115)$ is not statistically significant. It was also observed that there is no significant relationship between parameters such as participants' age and menopause onset with T-score.

Table 2

Pearson's correlation coefficients between T-score and participants' age, body mass, height, menopause onset and DCI

\begin{tabular}{|l|c|c|c|}
\hline & & $\begin{array}{c}\text { Lumbar spine } \\
\text { T-score }\end{array}$ & $\begin{array}{c}\text { Hip } \\
\text { T-score }\end{array}$ \\
\hline \multirow{2}{*}{ DCI } & $r$ & -0.153 & -0.155 \\
\cline { 2 - 4 } & $p$ & 0.120 & 0.115 \\
\hline \multirow{2}{*}{ Age } & $r$ & -0.106 & -0.105 \\
\cline { 2 - 4 } & $p$ & 0.285 & 0.264 \\
\hline \multirow{2}{*}{ Height } & $r$ & 0.033 & 0.020 \\
\cline { 2 - 4 } & $p$ & 0.739 & 0.838 \\
\hline \multirow{2}{*}{ Body mass } & $r$ & $0.255^{* *}$ & $0.377^{* * *}$ \\
\cline { 2 - 4 } & $p$ & 0.009 & 0.000 \\
\hline \multirow{2}{*}{ BMI } & $r$ & $0.245^{*}$ & 0.000 \\
\cline { 2 - 4 } & $p$ & 0.012 & -0.058 \\
\hline \multirow{2}{*}{ Menopause onset } & $r$ & 0.029 & 0.556 \\
\cline { 2 - 4 } & $p$ & 0.771 & 0.000 \\
\hline
\end{tabular}

$n=104 ; r-$ Pearson's correlation coefficients; $\mathrm{p}$ - probability value;

* significance level at $\mathrm{p} \leq 0.05 ; * *$ significance level at $\mathrm{p} \leq 0.01 ; * * *$ significance level at $\mathrm{p}$ $\leq 0.001$ 
The significant positive correlation was found between the body mass and T-score of the spine $\left(r=0.255^{* *}, p=0.009\right)$, as well as T-score of the hip $\left(r=0.377^{* * *}, p=0.000\right)$. There was no statistically significant association between the height of the participants and T-score of the spine $(r=0.033, p=0.739)$; and between the height and T-score of the hip $(r=0.020$, $p=0.838$ ).

The significant correlation was also observed between BMI and T-score of the spine $\left(r=0.245^{*}, p=0.012\right)$, as well as T-score of the hip $\left(r=0.383^{* * *}, p=0.000\right)$.

Aiming to get insight into the changes of the bone density in the course of the age, the data were rearranged to demonstrate a possible difference in the T-score values between age groups. We divided the participants into 3 age groups: (1) from 49 to 58 years old, (2) from 59 to 68 years old and (3) 69 and older. The data are presented in Table 3.

Table 3

T-score of the lumbar spine and hip in different participants' age groups

\begin{tabular}{|c|c|c|c|}
\cline { 2 - 4 } \multicolumn{1}{c|}{} & & Hip T-score & Spine T-score \\
\hline Age range & $\mathbf{n}$ & \multicolumn{2}{|c|}{$\overline{\mathbf{x}}$} \\
\hline $49-58$ & 28 & -1.679 & -1.657 \\
\hline $59-68$ & 41 & -1.566 & -1.824 \\
\hline $69+$ & 35 & -1.951 & -1.983 \\
\hline
\end{tabular}

$n$-number of participants, $\bar{x}-$ mean

In order to get insight into the occurrence of (1) participants' previous fractures and (2) fractures among close family members, we also grouped data on the grounds of bone density findings: participants with osteoporosis, osteopenia and normal bone mass (Table 4). It was concluded that 20 participants had previous fractures, and 9 participants reported history of family fractures. The data analysis showed that the majority of previous fractures occurred in respondents with diagnosed osteoporosis $(65 \%$ of the total number of reported previous fractures). The same group of participants also reported the biggest number of fractures among close family members (67\% of the total number of fracture histories).

\section{Personal and family history of fracture of the participants}

Table 4

\begin{tabular}{|c|c|c|}
\cline { 2 - 3 } \multicolumn{1}{c|}{} & $\begin{array}{c}\text { Previous personal } \\
\text { fractures }\end{array}$ & $\begin{array}{c}\text { Family history of } \\
\text { fractures }\end{array}$ \\
\hline Osteoporosis & $13(65 \%)$ & $6(67 \%)$ \\
\hline $\begin{array}{c}\text { Low bone mass } \\
\text { (osteopenia) }\end{array}$ & $6(30 \%)$ & $3(33 \%)$ \\
\hline Normal bone mass & $1(5 \%)$ & $0(0 \%)$ \\
\hline Total $(n=104)$ & $\mathbf{2 0}$ & $\mathbf{9}$ \\
\hline
\end{tabular}

The data regarding the risk factors of osteoporosis among the participants are shown in Table 5. The results showed that most of the participants i.e. $76.92 \%$ consume caffeine on regular daily basis, $88.46 \%$ do not consume alcohol at all, and $69.23 \%$ do not consume food with high amounts of salt. A relatively small number of the respondents are smokers $(12.5 \%)$, and $4.81 \%$ take corticosteroids therapy. $74.04 \%$ stated that they did not often have physical activity, and $40.38 \%$ stated that they were often exposed to sun. 
Nutrition is consider to be an important modifiable factor in the development and preservation of bone mass and the prevention and treatment of osteoporosis [13]. In addition, calcium is a key element in the formation of bones and in reaching peak bone mass, and as a result its role is very important in the primary prevention of osteoporosis [14]. Calcium intake in adulthood and postmenopause influences the level of age-related bone loss. Therefore, ensuring adequate calcium intake in postmenopausal women is an important step in prevention and treatment of osteoporosis. The mean daily calcium intake among our study participants, assessed using a validated FFQ, was $854.3 \pm 260.4 \mathrm{mg}$, which is below the Recommended nutrient intakes (RNIs): the RNI of $1000 \mathrm{mg}$ /day for premenopausal women, and the RNI of $1300 \mathrm{mg}$ /day for menopausal women over 50 years old [15]. The lowest determined daily calcium intake among participants was $366 \mathrm{mg} /$ day, while the highest was $1686 \mathrm{mg} /$ day. According to the previously reported data calcium intake can effectively postpone the tendency of BMD decrease in postmenopausal women [16]. Several studies have demonstrated that a calcium intake dose less than $800 \mathrm{mg} /$ day is associated with increased BMD loss in post- and perimenopausal women, and daily $1200 \mathrm{mg}$ calcium is suggested as a beneficial dosage $[14,16]$.

Risk factors of osteoporosis among the participants

Table 5

\begin{tabular}{|c|c|c|}
\hline $\begin{array}{l}\text { Previous personal } \\
\text { fractures }\end{array}$ & $\begin{array}{l}\text { Yes } \\
\text { No }\end{array}$ & $\begin{array}{l}20(19.23 \%) \\
84(80.77 \%)\end{array}$ \\
\hline $\begin{array}{l}\text { History of family } \\
\text { fractures }\end{array}$ & $\begin{array}{l}\text { Yes } \\
\text { No }\end{array}$ & $\begin{array}{c}9(8.65 \%) \\
95(91.35 \%)\end{array}$ \\
\hline Corticosteroids therapy & $\begin{array}{l}\text { Yes } \\
\text { No }\end{array}$ & $\begin{array}{c}5(4.81 \%) \\
99(95.19 \%)\end{array}$ \\
\hline Physical exercise & $\begin{array}{c}\text { Daily } \\
\text { 1-2 times a week } \\
\text { Sometimes } \\
\text { No }\end{array}$ & $\begin{array}{c}2(1.92 \%) \\
6(5.77 \%) \\
19(18.27 \%) \\
77(74.04 \%)\end{array}$ \\
\hline Sun exposure & $\begin{array}{l}\text { Yes } \\
\text { No }\end{array}$ & $\begin{array}{l}42(40.38 \%) \\
62(59.62 \%)\end{array}$ \\
\hline Smoking & $\begin{array}{l}\text { Up to } 10 \text { cigarettes a day } \\
\text { Up to } 20 \text { cigarettes a day } \\
\text { Up to } 30 \text { cigarettes a day } \\
\text { Non-smoking persons }\end{array}$ & $\begin{array}{c}6(5.77 \%) \\
6(5.77 \%) \\
1(0.96 \%) \\
91(87.50 \%)\end{array}$ \\
\hline Alcoholic drinks & $\begin{array}{c}\text { Daily } \\
1-2 \text { times a week } \\
\text { Sometimes } \\
\text { No }\end{array}$ & $\begin{array}{c}4(3.85 \%) \\
1(0.96 \%) \\
7(6.73 \%) \\
92(88.46 \%)\end{array}$ \\
\hline Caffeinated beverages & $\begin{array}{c}\text { Daily } \\
\text { 3-5 times a week } \\
\text { Sometimes } \\
\text { No }\end{array}$ & $\begin{array}{c}80(76.92 \%) \\
1(0.96 \%) \\
4(3.85 \%) \\
19(18.27 \%)\end{array}$ \\
\hline $\begin{array}{c}\text { Food with high amounts } \\
\text { of salt }\end{array}$ & $\begin{array}{l}\text { Yes } \\
\text { No }\end{array}$ & $\begin{array}{l}32(30.77 \%) \\
72(69.23 \%)\end{array}$ \\
\hline
\end{tabular}


The results obtained in our study showed that the highest calcium amount consumed through diet in participants comes from milk and dairy products. The drinking water was another significant source of dietary calcium. The important source of calcium in their diets from the vegetable group was spinach, and from the fruit group it was oranges. Also, participants consume tinned sardines (with bones) which are a rich source of calcium. Our results suggest that education about the importance of dietary calcium in prevention of osteoporosis is necessary as well as gaining knowledge of the food supplies which are rich sources of calcium, in order to improve the dietary calcium intake. Education is especially important if taken into consideration that the persons with poor knowledge and with low social economic status are four to five times at larger risk to consume less calcium through nutrition compared to others [17].

The results obtained in this study confirmed that higher body mass and BMI in participants are associated with higher bone density, reported using T-scores. These findings are consistent with other studies emphasing the bone mass and the BMI as a powerful determinants of bone loss. Namely, in the research of Igić and Zvekić-Svorcan [18] it is confirmed that there is statistically significant association between the body mass and the Tscore of the hip, as well as the T-score of the spine. Finkelstein et al. [19] have found that during the late peri- and postmenopause, rates of spine and hip bone loss was approximately $35-55 \%$ slower in women in the top vs. the bottom tertile of body mass. It is possible that the reasons why higher body weight is associated with slower rates of bone loss are the increased production of estrogens by adipose tissue or/and the regulatory role of osteocytes in order to reduce bone resorption as response to greater mechanical loading [19].

Low BMI values are considered to be a risk determinant for osteoporosis occurrence. In our research, none of the female respondents had BMI value $<18,5 \mathrm{~kg} / \mathrm{m}^{2}$. The statistically significant association between the BMI and the T-score of the hip, as well as the T-score of the spine that was identified in our study is also confirmed in the research of Zvekić-Svorcan et al. [20], showing that there is a relationship between persons' BMI and their lumbar spine and hip T-scores i.e. there is association between the decreased BMD and the low BMI [20]. Kang et al. [21] found that the hip bone strength deteriorated with aging and enhanced with higher BMI and longer time of years of menstruation in Chinese postmenopausal women. The results from their study supported that BMD is in positive relationship with BMI which means that higher BMI values are associated with stronger and more powerful hip bones. In addition, low body mass index (BMI) is a well-determined risk factor for fractures, and fracture risk differs according to fracture site [22]. De Laet et al. [23] have found that the relationship between BMI and the fracture risk is non-linear, and the highest risk rate is at BMI values $<20 \mathrm{~kg} / \mathrm{m}^{2}$ and slight decrease of the risk is noticed at the level $>25 \mathrm{~kg} / \mathrm{m}^{2}$. Based on these results, special attention should be given to thin women who are at increased risk of bone loss.

The majority of previous fractures in our study occurred in women with diagnosed osteoporosis ( $65 \%$ of the total number of reported previous fractures), compared with the participants with osteopenia $(30 \%)$ and with normal bone mass $(5 \%)$. The participants with osteoporosis also reported the biggest number of fractures in their close family $(67 \%$ of the total number of fracture histories registered in the research). These results are consistent with literature data and demonstrated that reduced bone density among women is related with existence of previous personal fractures, as well as with family history of fracture in diagnosed persons. De Laet et al. [24] showed that the family history of fracture is strongly connected with the risk of fracture occurrence. Also, Invernizzi et al. [25] found an increased risk of fractures in women with a positive family history of fragility fractures. In the research 
of Vasic et al. [26] the authors concluded that the presence of vertebral fractures is a risk factor for future fracture occurrence. Nevertheless, this dependence is not always present, and in a research which involved 122 respondents with average age $66.85 \pm 8.42$, the authors Igić and Zvekić-Svorcan [18] emphasize that they had not determined statistically significant difference between the respondents with or without history of family fractures and the occurrence of osteoporosis/osteopenia.

The rearranging of the obtained $\mathrm{T}$-score values in our study within age groups confirmed that the bone density decreases from the youngest to the oldest age group of participants; only exception was found for the hip T-score in the age group 59 to 68. This study's findings are generally consistent with studies that have found that the reduction of BMD depends on age and choice of measurement site $[27,28]$.

Women in our study reported to experience natural menopause fairly early, at about mean age 47.5 . From the total of 104 participants, $76 \%$ entered menopause before reaching 50 . The statistical analysis of our results showed that there is no significant relationship between the menopause onset and the BMD, reported in the T-score at the lumbar spine $(r=0.029$, $p=0.771)$ or hip $(r=-0.058, p=0.556)$. Contrary to our results, Zvekić-Svorcan et al. [29] observed statistically high connection between menopause onset and bone mineral density, as well as between menopause duration and bone mineral density. Other authors also reported that early menopause is an important risk factor for osteoporosis occurrence [30,31]. We can speculate that the reason why our results didn't demonstrate significant correlation between the menopause onset and the BMD could be the low average age at menopause onset among the selected women in our study group.

The insight into exogenous risk factors of osteoporosis in this study showed that a small percentage of the participants: were smokers $(12,5 \%)$, used corticosteroids therapy $(4.81 \%)$ and consumed alcohol (11.54\%), but the percentage of participants who consume caffeine on daily basis was rather high i.e. $76.92 \%$. Smoking, corticosteroids therapy and alcohol and caffeine consumption are well-known risk factors that may be associated with low bone density and increased risk of osteoporotic fractures [32, 33, 34, 18]. Identifying major exogenous risk factors on national level and understanding their impact on bone loss in postmenopausal women need to be further elucidated.

Most of the participants in our study reported insufficient physical activity and sun exposure. Insufficient activity was defined as person not meeting the WHO recommendations on physical activity for health [35]. Among participants, 74.04\% ( $\mathrm{n}=77)$ reported to never exercise. Only two women $(1.92 \%)$ reported they practise physical exercise every day. Studies have shown that poor dairy calcium intake, along with low physical activity are key risk determinants of osteoporosis and fracture [17]. Regular physical activity that maintains or increases muscle strength, coordination and balance is universal recommendation for the prevention and treatment of osteoporosis, as well as for reducing the risk of falls and fractures. Many authors reported that increased physical activity levels are associated with reduced risk for low bone density in postmenopausal women [36, 37]. In order to change the physical inactivity profile of Macedonian postmenopausal women determined in our study, strategies should be created to address this group of patients.

\section{Conclusion}

The mean daily calcium intake among our study participants was $854.3 \pm 260.4 \mathrm{mg}$ which is below the calcium recommended nutrient intake (RNI) for postmenopausal women. This study's findings confirmed that the reduction of the bone mineral density (BMD), reported 
using T-scores, depends on age and choice of measurement site. Education on the importance of calcium in the diet and knowledge on the lifestyle factors that affect bone loss are needed toward decreasing risk for osteoporosis and related fractures in postmenopausal women. The education should cover different age categories of women because the bone mass in later life depends on the peak bone mass achieved during growth and the rate of subsequent age-related bone loss. In order to change the physical inactivity profile of Macedonian postmenopausal women and their nutritional habits, preventive strategies should be created to address this group of patients.

Identifying major exogenous risk factors on national level and understanding their impact on bone loss in postmenopausal women need to be further elucidated.

\section{References}

1. Digitale E., Hathaway C., Heneman K., Cherr SZ. (2008), Nutrition and health Info Sheet: Calcium and Osteoporosis, ANR Publication 8138, pp. 1-5.

2. Lane N.E. (2017), Metabolic Bone Disease, Kelley and Firestein's Textbook of Rheumatology, 1730-1750.

3. Jones A., Sheri-Zidenberg-Cherr SZ. (2016), Nutrition and health Info Sheet: Osteoporosis, Center for Nutrition in Schools, Department of Nutrition University of California, Davis.

4. Janiszewska M., Firlej E., Kieliszek D.Z., Dziedzic M. (2016), Knowledge about osteoporosis prevention among women screened by bone densitometry, $\operatorname{Prz}$ Menopauzalny, 15(2), pp. 96-103.

5. Curtis E.M., Moon R.J., Harvey N.C., Cooper, C. (2017), Reprint of: The impact of fragility fracture and approaches to osteoporosis risk assessment worldwide, Int $J$ Orthop Trauma Nurs, 26, pp. 7-17.

6. WHO Study Group (2003), Prevention and menagment of osteoporosis, WHO Tehnical Report Series, No 921. Geneva, World health Organisation.

7. Webster-Gandy J., Madden, A., Holdsworth M. (2006), Oxford Handbook of Nutrition and Dietetics, Oxford University Press.

8. Cashman K.D. (2007), Diet, Nutrition, and Bone Health, J. Nutr., 137, pp. 2507S2512S.

9. Allen L., de Benoist B., Dary O., Hurrell R. (2006), Guidelines on food fortification with micronutrients, World Health Organization and Food and Agriculture Organization of the United Nations, NLM classification: QU 145, pp. 81-86.

10. Zhu K., Prince R.L. (2012), Calcium and bone, Clin Biochem., 45 (12), pp. 936-942.

11. Sutlovic D., Boric I., Sliskovic L., Popovic M., Knezovic Z., Nikolic I., Vucinovic A., Vucinovic Z. (2016), Bone mineral density of skeletal remains: Discordant results between chemical analysis and DXA method, Leg Med (Tokyo), 20, pp. 18-22.

12. Šatalić Z., Colić Barić, I., Cecić I., Keser I. (2007), Short food frequency questionnaire can discriminate inadequate and adequate calcium intake in Croatian postmenopausal women, Nutr Res, 27, pp. 542-547.

13. Ilich J.Z., Brownbill R.A., Tamborini L. (2003), Bone and nutrition in elderly women: Protein, energy, and calcium as main determinants of bone mineral density, Eur J Clin Nutr, 57, pp. 554-565.

14. Ströhle A., Hadji P., Hahn A. (2015), Calcium and bone health-goodbye, calcium supplements, Climacteric, 18(5), pp. 702-14. 
15. Vitamin and mineral requirements in human nutrition. Report of the Joint FAO/WHO Expert Consultation. World Health Organization, 2004.

16. Wu J., Xu L., Lv Y., Dong L., Zheng Q., Li L. (2017), Quantitative analysis of efficacy and associated factors of calcium intake on bone mineral density in postmenopausal women, Osteoporos Int., 28(6), pp. 2003-2010.

17. Raj J.P., Oommen A.M., Paul T.V. (2015), Dietary calcium intake and physical activity levels among urban South Indian postmenopausal women, J Family Med Prim Care, 4(3), pp. 461-4.

18. Igic N., Zvekic-Svorcan J. (2015), The impact of risk factors on the reduction of bone mineral density in postmenopausal women, MD-Medical data, 7(2), pp. 119-126.

19. Finkelstein J.S., Brockwell S.E., Mehta V., et al. (2007), Bone mineral density changes during the menopause transition in a multiethnic cohort of women, J Clin Endocrinol Metab., 93(3), pp. 861-868.

20. Zvekić-Svorcan J., Filipović K., Stanimirov B., Elez I., Repac V. (2013), Importance of the body mass index in development of osteoporosis, Glasnik Antropoloskog drustva Srbije, 48, pp. 49-56.

21. Kang H., Chen Y.M., Han G., Huang H., Chen W.Q., Wang X., Zhu Y.Y., Xiao S.M. (2016), Associations of Age, BMI, and Years of Menstruation with Proximal Femur Strength in Chinese Postmenopausal Women: A Cross-Sectional Study, Int J Environ Res Public Health, 13(2), pp. 157.

22. Compston J.E., Flahive J., Hosmer D.W., Watts N.B., Siris E.S., Silverman S., et all. (2014), Relationship of Weight, Height, and Body Mass Index With Fracture Risk at Different Sites in Postmenopausal Women: The Global Longitudinal Study of Osteoporosis in Women (GLOW), J Bone Mineral Res., 29(2), pp 487-493.

23. De Laet C., Kanis J.A., Oden A., Johanson H., Johnell O., Delmas P., Eisman J.A., Kroger H., Fujiwara S., Garnero P., McCloskey E.V., Mellstrom D., Melton L.J. 3rd, Meunier P.J., Pols H.A., Reeve J., Silman A., Tenenhouse A. (2005), Body mass index as a predictor of fracture risk: a meta-analysis, Osteoporos Int., 16(11), pp. 1330-1338.

24. De Laet C., Kanis J.A., Johansson H., Oden A., Johnell O., Eisman J.A., et al. (2004), A family history of fracture and fracture risk a meta analysis, Bone, 35, pp. 1029-3.

25. Invernizzi M., Noale M., Iolascon G., Letizia Mauro G., Falaschi P., Arioli G., Maggi S., Cisari C. (2017), Vertebral fractures, function and cognitive status in osteoporotic hip fractured women: The FOCUS study, European Geriatric Medicine, 8 (1), pp. 48 53.

26. Vasić J., Gojković F., Zvekić-Svorcan J., Nikčević L., Kučević I., Janković T. (2013), The incidence and level of osteoporotic vertebral fractures in relation to age, $M D-$ Medical data, 5(4), pp. 335-41.

27. Boschitsch E.P., Durchschlag E., Dimai H.P. (2017), Age-related prevalence of osteoporosis and fragility fractures: real-world data from an Austrian Menopause and Osteoporosis Clinic, Climacteric, 20(2), pp. 157-163.

28. Ilic Stojanovic O., Vuceljic M., Lazovic, M., Gajic M., Radosavljevic N., Nikolic D., Andjic M., Spiroski D., Vujovic S. (2017), Bone mineral density at different sites and vertebral fractures in Serbian postmenopausal women, Climacteric, 20(1), pp. 37-43.

29. Zvekic-Svorcan J., Jankovic T., Filipovic K., Gojkov-Zigic O., Tot-Veres K., SubinTeodosijevic S. (2013), Connection of menopause onset and duration on the level of mineral bone density, MD - Medical data, 5(3), pp. 217-21.

30. Pavel OR., Popesku M., Novac L., Mogoanta L., Pavel LP., Vicas RM., Traistaru MR. (2016), Postmenopausal osteoporosis - clinical, biological and histopathological aspects, Rom J Morphol Embryol, 57(1), pp. 121-130. 
31. McClung MR. (2015), Late skeletal effects of early menopause, Menopause, 22(10), pp. $1027-9$.

32. Hallström H., Wolk A., Glynn A., Michaëlsson K. (2006), Coffee, tea and caffeine consumption in relation to osteoporotic fracture risk in a cohort of Swedish women, Osteoporos. Int., 17, pp. 1055-1064.

33. Brook J.S., Balka E.B., Zhang C. (2012), The smoking patterns of women in their forties: their relationship to later osteoporosis, Psychol Rep., 110(2), pp.351-62.

34. Kim K.H., Lee C.M., Park S.M., Cho B., Chang Y., Park S.G., et al. (2013), Secondhand smoke exposure and osteoporosis in never-smoking postmenopausal women: the Fourth Korea National Health and Nutrition Examination Survey, Osteoporos Int., 24(2), pp. 523-32.

35. World Health Organization (2010), Global recommendations on physical activity for health, Geneva.

36. Dallanezi G., Freire B.F., Nahás E.A., Nahás-Neto J., Corrente J.E., Mazeto G.M.F.S. (2016), Physical Activity Level of Post-menopausal Women with Low Bone Mineral Density, Rev Bras Ginecol Obstet., 38(5), pp. 225-30.

37. DeFina L.F., Leonard D., Willis B.L., Barlow C., Finley C.E., Jenkins M.R., Pence B.C., Zhang Y., Chyu M.C., Lewiecki E.M., Shen C.L. (2016), High Cardiorespiratory Fitness Is Associated with Reduced Risk of Low Bone Density in Postmenopausal Women, $J$ Womens Health (Larchmt), 25(10), pp. 1073-1080. 